\title{
Challenges of Teaching Economics in International Exchange Programs
}

\author{
Augustin Mbemba ${ }^{1}$ \\ ${ }^{1}$ Department of Economics, Robins Business of School, University of Richmond, USA \\ Correspondence: Augustin Mbemba, Department of Economics, Robins Business of School, University of \\ Richmond, VA 23173 USA. E-mail: mbembaaugustin@hotmail.com
}

Received: May 21, 2014

doi:10.5539/ijef.v6n8p68
Accepted: June 6, 2014

Online Published: July 25, 2014

\begin{abstract}
For decades, many faculty and students visited all the continents through international exchange programs. As proven by the well-known programs, the Fulbright Programs in the U.S and the European Erasmus Programs have significantly contributed in the development of international exchange programs. Today, with the accelerating rate of globalization, Business Schools are focusing their effort on faculty and students' ability to move using global research partnerships, and improving their curriculum to reach their goals. In the meantime, with the current labor market requiring graduates to know one or more foreign languages and to have intercultural skills, having the opportunities to interconnect in global setting, Universities and Colleges are mostly emphasizing on internationalization and exchange programs. Also, the number of students involved in global programs overseas significantly increased during the last decades until now. As globalization involves interconnected political, economical, cultural and social aspects, teaching economics in exchange programs is also affected and other subject as well. Relevant teaching strategies and methods have to be implemented to address the challenges faced by the international students and faculties with diverse cultural and academic background. This paper discusses the issue of why and how faculty should teach in international program? It also investigates different approaches of teaching economics in exchange programs including an understanding of different cultures and societies in learning and teaching environment. It finally explores how international exchange programs have persuaded Faculty across many Universities and higher education institutions to develop teaching styles and new courses emphasizing global economics or international Business.
\end{abstract}

Keywords: global, international, exchange programs, economics, teaching, research

\section{Introduction}

The globalization of the business world calls for increased globalization in business education. Global Teaching is an effective way to realize internationalization through business schools, but there are many challenges related to teaching economics and other subjects abroad that need to be resolved. In fact, lack of information about best practices of teaching overseas in exchange programs occurs in academic arena. Thus, teaching economics in international exchange programs remains an overwhelming task. One of the challenges economics professors are facing in international arena, is to go beyond the perception of economics as an abstract theoretical and highly quantitative subject and to add international skills in their backgrounds. The World just came out of the worst financial crisis that has created both teaching economics challenges and opportunities in international exchange programs. The economic climate has been challenging for higher education institutions, students and their families, and faculty has to help students understanding not only the domestic economic crisis, but also the global crisis. At the same time, international education is expanding to include ever growing numbers of students, and universities are developing comprehensive internationalization plans to incorporate global perspectives into all aspects of their campuses. Faculty and staff involved in exchange programs are responding to the growing need in many institutions. Our worldwide network of higher education institutions ensures that affordable and diverse opportunities are available to students and faculty regardless of their socio-economic background.

Globalization has impacted the way we teach economics in international exchange programs. Faculty are traveling extensively in all continents such as Europe, Asia, Africa, South America throughout many academic projects related to teaching, research and outreach development. The impact of these programs goes beyond the many personal and transformational insights they gained. International collaboration among Universities, 
faculties, visiting guest-speakers, students may be included in the curriculum. For example, during the global financial crisis, exchange program students from the United States tremendously learned about the macroeconomic responses adopted by emerging nations (Brazil, Russia, China, Ghana, South Africa). Their understanding of global crisis was facilitated by the international involvement of faculty who improved their teaching styles in exchange programs. Although fast-developing information technologies may provide ways to assist teachers and students without participating in exchange programs, nevertheless, interconnecting with others is a complement of being personally committed in teaching economics in unfamiliar cultures. Our intent in this paper is to provide avenues of advancing teaching economics. The accomplishment of this mission depends on the goals and constraints of academic institutions, and the adoption of several approaches. In particular, an institution's mission, vision, values and the availability of resources play a key role in determining extent of exchange programs and the approach suited to achieve that goal. Making the subject of Economics interesting in exchange programs and relevant to domestic and foreign students remains an overwhelming and exciting task.

\section{What Is an International Exchange Program?}

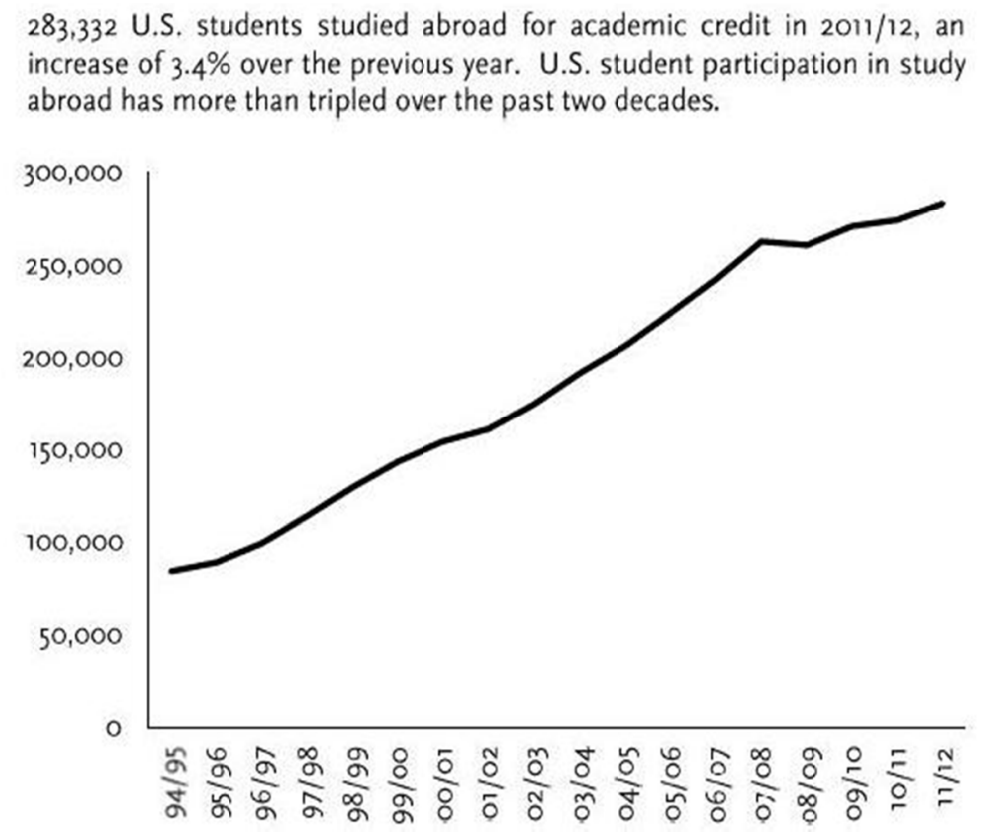

Figure 1. U.S. study abroad trends

Note. OpenDoors Report 2013 "Fast Facts".

In general, an international exchange program is an enhancing experience. It impacts both personal and professional life, encourages creative ideas, sustains relationships, and strengthens multicultural knowledge. Teaching abroad or leading a research overseas in a different environment brings new and rewarding challenges. In the same time, instructors are serving as ambassadors for their home universities, and address important foundations for future exchanges and collaborations. Also, exchange Programs offer different ways for faculty and staff to interact domestically and internationally other colleagues. Various options from short-term to long-term exchange visits, such as the Fulbright programs, offer unique opportunities to participants. Recently, many researchers have took a stand on exchange program, debating on how to implement and to improve it when it comes to some factors as the socio-economic background of the countries visited, the social and cultural aspects of individuals. Teaching styles that do not consider that value are slandered. The main objective of teachers is to handle and to support students in a learning process. Consequently, so they may feel positively, fairly encouraged by Instructors who have international experience. An international exchange program represents an opportunity for faculty and students to gain international experience. Many European and American colleges and Universities welcome global faculty to teach one or two course. Due to the fact to the duration of visits may vary, Business schools adjust their curriculum or programs according to the availability of their human and financial resources. Faculties returning to their home campuses are ambassadors who advocate international exchange programs or internationalization initiatives. They tend to improve these programs, 
suggesting new approaches and strategies. Raby (1996) defined the global exchange programs as the possibilities of traveling or temporarily moving abroad for professional purpose such as teaching and learning during a specific period. Some Universities and Colleges that have those programs are directly participating in the process of gaining international experience. Meanwhile researchers coming to the United States' higher education institutions are also bringing enriching experience making in-class debates more dynamic. They also interconnect with other students in academic and learning groups. This process is uniquely helping universities and colleges in several ways. It suggests a wealth of learning opportunities in various cultural environments.

Cultural diversity in a classroom help students and faculty to learn about other cultures as many may be called to act in global economy. Experience of diversity, however, is not limited to the campuses, but it extends to the opportunities that may facilitate faculty or student's integration in any country. Those opportunities are given throughout partnerships around the world, the exchange programs, volunteering activities with communities. On the students side, according to the 2013 Open Doors Report (Note 1) specifies the importance of learning in international environment. For instance, the number of international students studying in the United States increased by seven percent to a record high of 819,644 students in a year from 2012 to 2013, while U.S. students learning overseas increased by three percent reaching 283,000 in the same period (Tables I \& II). The number of U.S. students who studied abroad for academic credit increased by three percent to 283,332 students in 2011/12 (Table I \& II), a higher rate of growth than the one percent increase the previous year.

Table 1. U.S. students studying abroad

\begin{tabular}{cclcccc}
\hline Rank & Place of origin & $\mathbf{2 0 1 0 / 1 1}$ & $\mathbf{2 0 1 1 / 1 2}$ & $\mathbf{\%}$ of Total & \%Change \\
\hline 1 & TOTAL & $\mathbf{2 7 3 , 9 9 6}$ & $\mathbf{2 8 3 , 3 3 2}$ & $\mathbf{1 0 0}$ & $\mathbf{3 . 4}$ \\
\hline 2 & Inited Kingdom & 33,182 & 34,660 & 12.2 & 4.5 \\
3 & Spain & 30,361 & 29,645 & 10.5 & -2.4 \\
4 & France & 25,965 & 26,480 & 9.3 & 2.0 \\
5 & China & 17,019 & 17,168 & 6,1 & 0.9 \\
6 & Germany & 9,018 & 14,887 & 5.3 & 2.0 \\
7 & Australia & 9,736 & 9,324 & 3.3 & 3.9 \\
8 & Costa Rica & 7,230 & 7,900 & 2.8 & -4.2 \\
9 & Ireland & 7,007 & 7,640 & 2.7 & 9.3 \\
10 & Japan & 4,134 & 5,283 & 1.9 & 27.8 \\
11 & Argentina & 4,589 & 4,763 & 1.7 & 3.8 \\
12 & India & 4,345 & 4,593 & 1.6 & 5.7 \\
13 & South Africa & 4,337 & 4,540 & 1.6 & 4.7 \\
14 & Brazil & 3,485 & 4.060 & 1.4 & 16.5 \\
15 & Mexico & 4,167 & 3,815 & 1.3 & -8.4 \\
16 & Ecuador & 3,107 & 3,572 & 1.3 & 15.0 \\
17 & Czech Republic & 3,291 & 3,477 & 1.2 & 5.7 \\
18 & Israel & 3,441 & 3,189 & 1.1 & -7.3 \\
19 & Chile & 3,280 & 3,064 & 1.1 & -6.6 \\
20 & New Zealand & 2,900 & 2,969 & 1.0 & 2.4 \\
21 & Denmark & 2,478 & 2,876 & 1.0 & 16.1 \\
22 & Greece & 3,428 & 2,701 & 1.0 & -21.2 \\
23 & South Korea & 2,487 & 2,695 & 1.0 & 8.4 \\
24 & Peru & 2,448 & 2,680 & 0.9 & 9.5 \\
25 & Austria & 2,736 & 2,657 & 0.9 & -2.9 \\
\hline & & & & &
\end{tabular}

Note. https://www.iie.org/opendoors2013.

According to the same report, more U.S. students travelled to South America and China, using exchange programs. Japan registered a decline of exchange programs participants because of the earthquake and tsunami of March 2011. The number of USA students has significantly increase over the twenty years, attaining a record in 2012.

\section{Importance and Goals: Why Should Faculty Consider Teaching Abroad?}

The benefits and values of teaching in international exchange program must be simultaneously coordinated 
according to the students and faculty's interests. Faculty should consider teaching in exchange visit or summer program abroad for many reasons. First, the globalization of the economy has brought new challenges for faculty and students as they compete now in global market. For instance, it is beneficial for individuals who perceive teaching abroad as another opportunity to enrich their experience in order to find a better job. Those who already have been in exchange programs, gained ability to overcome issues related to the language barriers, cultural diversity, solving conflicts under adverse situations have comparative and absolute advantages in marketplace. He will discover new environment with diverse cultures. Second, international exchange program facilitates individual growth and professional development. It represents another advantage for both students and faculty. After Studying or teaching abroad, participants considerably improve their teaching styles, techniques and methods used in the classroom. Also, more international real cases studies are used as examples for the benefits of students. Third, the Fulbright programs as well other exchange programs build sustainable networks or partnerships, and open doors to professional opportunities and international careers. Third, international exchange program is one of the practical learning and teaching method making the instructor, an asset for colleges and universities. Personally, my international teaching experiences in France considerably improved my teaching-learning in the United States. According to Hall (2007), it is as important for faculty members to teach abroad as much as it is for students to study abroad. I learned important and life lessons from his teaching abroad experiences that I could not have learned otherwise. In addition to his own personal learning experiences, I feel that my teaching styles and professional skills in the United States. have been enhanced because of my teaching abroad experiences. This sentiment is corroborated by a study by Finkelstein and Chen (cited in the AACSB Report, 2011), which found a positive correlation between a faculty member incorporating international issues into the classroom and the amount of time the faculty member had spent abroad after earning an undergraduate degree. Hall (2007) asserted that universities should put the same effort into developing faculty exchanges as they do for arranging study abroad experiences for students. However, as Hall pointed out, since universities have tended to put their emphasis on facilitating study abroad experiences for students, faculties are often left to develop their own teaching exchange experiences. The AACSB globalization report again mentions that schools focus more on globalizing the learning experiences of students, but often neglect to put the same emphasis on ensuring faculty have global developmental opportunities. In the same time, Clark and Arbel (1993) noted that to globalize faculty, universities should require more international faculty exchanges and sabbaticals. These institutions may have more international faculty members, and use industry professionals with global experience in the classrooms. When considering the increase of exchange faculty effectiveness abroad, several institutional practices shall be recommended and discussed. Business schools can be viewed as having new campuses in foreign countries, but this strategy is only the fulfillment of one aspect of globalization. Broadly, strategies of globalization include offering study abroad opportunities for students, adding global curriculum, and internationalizing the faculty. Although all facets are important in the globalization of business schools, we are addressing the issue of internationalizing the faculty. We consider that International exchange programs community tries to fulfill at least four major goals as explained by the following figure.

As we previously specified, global education supports partners "learning expeditions" for their faculty. Some provide grants to support faculty travel. Schools with multiple campuses in multiple countries may ask faculty to teach at their campuses in other countries for the immersion into a different culture. Another approach is to bring international visiting faculty to campus. The interaction with the visiting faculty member will help faculty develop more global awareness. It also helps develop the connections between schools and it encourages global research opportunities. These strategies for global education include the management of faculty. For instance, the context, including the structure and processes, in which faculty operate will impact their ability to add to the globalization of the business school. The extent to which the business school provides opportunities for interaction among the faculty who are interested in international issues and research provides a context in which globalization can flourish. For example, some schools develop a department of international business in which faculty with global interest can collaborate. Incentives may also be used to encourage globalization. Promotion, tenure, and grant support are examples of incentives that might be used. Finally, business schools have to figure out the best approach in order to implement their plans. 


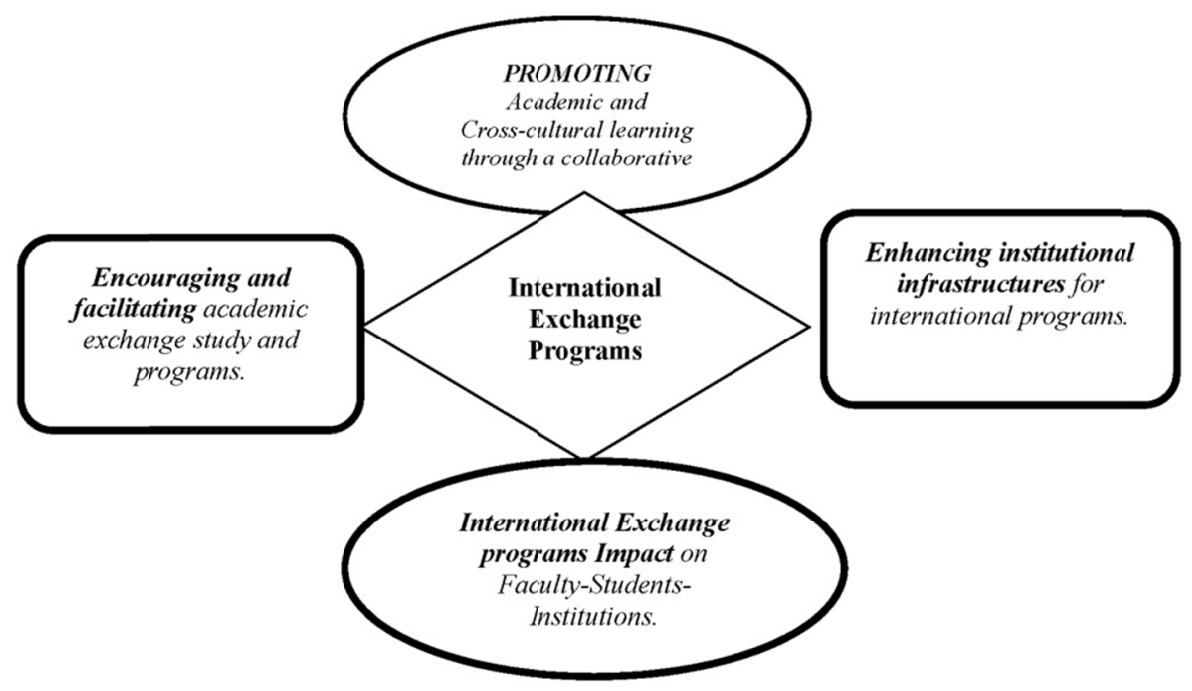

Figure 2. Exchange programs goals

\section{Different Approches and Types of International Exchange Programs}

A response of higher education institutions to globalization requires an internationalization of curriculum. Through internationalizing curriculum, Schools of Business expect to improve teaching and learning about economics, international business and to increase their stakeholders' opportunities to compete in global marketplace. As instructors work with diverse students in classrooms, researching or advising, they are likely to encounter individuals who would benefit from an exchange opportunity. Various methods have been discussed by researchers in the economic debate. From the choice the exchange program, to its implementation, it is critical for the faculty to have a support of his staff, dean or department head. The infusion approach initiated and developed by several authors Mestenhauser (1998); Satterlee (1997); Kwok and Arpen (1994); Kendrick (1993). This method focuses on the sum of courses related to globalization. Other aspects such as cultural, environmental aspects of countries are also infused. Economics Professors involved in exchange programs may adjust the content of their lectures for many reasons. With this method, students and faculty will have a better understanding of the regions in which they plan to conduct an exchange program. Therefore, participants feel more confident about having the required background to teach or to study in a foreign country. Therefore, it is critical for economics faculty involved in exchange programs to have specific knowledge of a country's institutions before one can understand its economy and meaningfully talk about policy. This direct approach has also its own challenges. One of them is to figure out whether or not there is a clear department-wide adoption of the strategies that need to be addressed before any implementation. Infusing courses is not enough to be successful during a visit abroad; this strategy cannot be done by the sole faculty or student. It should be adopted by the entire department staff. Sometimes, business schools choose to include ore or two international business courses in the curriculum because they do not have a faculty who can participate in exchange program. In this case the infusion approach appears to be just an addition of courses because of time pressure and other requirements. For example, globalizing or internationalizing the overall program requires an agreement of administrative staff and the entire head department's team as a chair and a dean.

In this context, this approach was extensively discussed by other (Raby 1996; Kwok \& Arpen, 1994) who suggest introducing new international programs in the curriculum. One of the major difficulties faced by business schools is time consuming of the new courses. Faculty who intends to travel for an exchange program may not have enough time to create these new courses that fit with the department's purpose. It is also costly as business schools have to hire new faculty in place of participants of international exchange program. Financial considerations linked to the development of new courses and the hiring of new faculty are major challenges for universities and colleges particularly in the time of economic uncertainty. Thus, international collaborations as another approach of internationalizing with foreign partners will significantly improve internationalizing curriculum. Developing networks cannot be done overnight. It is a commitment that requires time to be accomplished, exchanging students and faculty for short-term or long-term projects, having dual programs, and in certain case opening new campuses overseas. Other approaches suggest comparing cultural or economical 
countries' overviews (comparative method) in order to design the best approach before adjusting or adopting new global courses. There are different types of International Exchange programs. Business Schools, faculty or students may choose a short-term program, a mid-term program or a long-term program. In the United States, many professors choose Fulbright programs as one of the best opportunity to gain international experience. In the meantime, European professors have Erasmus programs to temporarily move inside or outside European borders. Most of French researchers benefited this program or a faculty-led Programs in a region, they academically and professionally well know. Other professors as visiting lectures have a one-year agreement with business schools to teach one or more courses. These programs may vary according to the duration of the stay in terms of long-term (typically academic year), medium-term (one or two quarters or one semester), or short terms.

For instance, European faculty may teach European Political Economics to US students while American professors educate European students on entrepreneurship using an American style. Practically, everyone is quick to say we need to broaden our outlook to include a world view, but few offer practical ways to do so. Faculties are the individuals who design their international course, and as ambassador of exchange programs, they advise students to participate at least in one-time program abroad. If students can perceive relevant input from their international faculty, they feel confident to study abroad in an exchange program. They must see a benefit to themselves in order to participate. Business schools may encourage faculty by paying the same compensation or incentives they earn at the domestic institution, in order to avoid financial discrepancies between salaries in overseas teaching abroad programs, and those received at home institution. Finally, business schools have to supply institutional and logistical support and administrative assistance to encourage faculty who have little international background.

\section{Organization and Strategies of Teaching Economics}

Teaching through exchange programs brings global perspectives to the faculty but one of challenges economics instructor has to focus on is for example to partner at different levels with foreign faculty, graduate students and staff. This is extremely important to all the partners involves in these programs because simply discussing best strategies on performance international business or economics as taught at home institution would not have the impact desired by foreign students and universities. Similarly, a foreign faculty in teaching exchange program in the United States has to be prepared to lecture in US Colleges and Universities. The AACSB Globalization Report noted three dimensions of faculty strategies for globalization: recruit, develop, and manage. To foster globalization, business schools recruiting strategy should include recruiting faculty that has interest in international issues. An additional recruiting strategy would be to recruit faculty who have international knowledge, perspectives, or experiences. A third recruiting strategy would be to recruit faculty for the international connections.

Table 2. Three dimensions of faculty strategies for globalization

\begin{tabular}{lll}
\hline RECRUIT & DEVELOP & MANAGE \\
\hline Interests/Values & Pedagogical Training & Faculty Interactions \\
Knowledge/Perspectives & Immersion/Experience & Incentives \\
Connections & Research Support & Deployment \\
\hline
\end{tabular}

The second type of faculty strategies for internationalizing is the strategies designed to provide global developmental opportunities for faculty. These developmental opportunities may be focused on three areas: pedagogical training, immersion/experiential learning, and research. Many faculty lack confidence in their ability to incorporate global topics into the curriculum. Providing pedagogical training in international content helps faculty feel more comfortable in globalizing the curriculum as discussed in the section below. The second developmental strategy is by immersion or experience. These experiences could be the encouragement of faculty to travel. Some schools provide "learning expeditions" for their faculty. Some provide grants to support faculty travel. Schools with multiple campuses in multiple countries may ask faculty to teach at their campuses in other countries for the immersion into a different culture. Another approach is to bring international visiting faculty to campus. The interaction with the visiting faculty member will help faculty develop more global awareness. It also helps develop the connections between schools. Teaching economics in exchange programs is very challenging as economics instructors need to understand many aspects of the economic environment or the macroeconomic overview of the country in which they are involved. 


\subsection{Differing Macro Policy Goals}

To deliver relevant lectures, they have to know the differences in Macro policies in developed, emerging countries, and developing countries. In the 1980s, the International monetary Fund unsuccessfully implemented many structural adjustment programs in developing countries because of lack of knowledge of the nature of local economies, macro policies goals, differences in Institutions, in political and economic systems such as laissez-faire, monetary and fiscal structures, cultural diversity programs. For instance, when discussing macro policy goals within Western developed economies or the United States; we usually used generally accepted macroeconomic goals (inflation, unemployment and growth rate). In Western developed countries, growth is desired because it holds unemployment down. If economics instructors in exchange programs in developing countries may realize that the weighting of goals is different. Faculty and students in some developing nations may have different priorities and challenges comparing to the same category of people in western nations.

\subsection{Economic Institutions}

Developing countries even some emerging countries may differ from developed economies in their macroeconomic institutions. In emerging countries such as Ghana or Nigeria, the economy is institutionally described by two interrelated areas (traditional area and a modern area as in Western country. This dual economy aspect leads to some dilemmas. For example, the largest part of the Nigerian population participates in the traditional area. Discussing unemployment concept may be problematic. In those countries and others, there is a large subsistence-farming economy. Subsistence farmers are not basically and technically unemployed, but often there are many people on the land that in economic terms, their contribution to output is negligible. These subsistence farmers are simply outside the market economy. In such cases, one would hardly want, or be able, to talk of an unemployment problem in the same way we discuss in the United States. Similarly, a foreign exchange Faculty will have the same challenges such as knowing the U.S monetary and financial systems.

\subsection{Differing in Financial and Monetary Systems and Policies}

Also, political systems, financial and monetary systems or the institutions that convert savings to investment, the institutions that collect taxes, social and cultural institutions are different may be different in African countries and Western countries. The nature of financial institutions such as the existence of Microfinance institutions in developing and emerging countries change the way we discuss macroeconomic policy in exchange programs. Mortgage market access and the conditionality of loans may be bas we may considered on different criteria that include political considerations. Discussing about monetary policy through the open market operations (the selling and the buying of bonds by the central bank) is not relevant as there is no market for government bonds as in the case in many developing countries. International financial sectors are sometimes similar to what is in Western financial institutions. For instance, a currency trading room in Ecuador or Nigeria looks similar to one in New-York or London. By contrast, often developing countries do not have the institutional structures with which to collect taxes. Western economies are many financial similarities but the specificities of the region in which central acts differ. Third, because of the structure of government in developing countries, many economists who, in developed economies, favor activist government policies may well favor classical laissez-faire policies for the same reasons that early Classical economist did because they have a profound distrust of the governments. That distrust must have limits. In the United States, entrepreneurship has been an engine of the economy while Europeans were hesitant to embrace small business ownership principles. Every job, even government jobs, can trace their origin to an entrepreneur. New businesses are also often the originators of new technologies and innovation. Faculty exchange programs in Europe hope to learn more about the 27 countries that form the European Union as well as entrepreneurial strategies that make Germany successful while other countries struggled during the recent financial crisis as Spain, Greece, Portugal, Italy even France. Working with Europeans students and colleagues at several universities, an economics Faculty has to keep in mind a basic question: "are some cultures in Europe less entrepreneurial than others and, if so, why?" Economics professors who have business management experience feel confident to explain microeconomics concepts using the American-style of entrepreneurship in market economy. One of the best courses instructors in this example could teach may be focusing on the theory of economic systems and European vs. U.S. Economic Policy. It is encouraging for instructors with business background to share their experience with students in European stage. The financial crisis period was one of teachable times that helped Students not only in international exchange programs to focus on macroeconomic topics.

In order to ensure the faculty exchange improvement process, the preparation stage is basically dedicated to minimize potential culture shock and to hasten the faculty's adaptation at the host institution. As in any other international assignment, it is advisable to start faculty. 
Table 3. Institutional practices to improve faculty exchange process

\begin{tabular}{lll}
\hline I. Preparation stage & II. Daily assistance & III. Process quality management \\
\hline
\end{tabular}

Preparation stage. Representing the core part of the faculty exchange improvement process, the preparation stage is basically dedicated to minimize potential culture shock and to hasten the faculty's adaptation at the host institution. As in any other international assignment, it is advisable to start faculty exchange process with special preparation training provided well before the stay. The training tends to have three components (Cavusgil et al., 2008): a) research areas-include historical, political, economical, and environmental facts of the host institution and nation, b)-practical facts-required knowledge and abilities to function effectively in a host-nation, including logistics preparation c)-cross-cultural awareness-Being able and willing to interact with populations with different cultural background. All mentioned training types, as well as methods, are welcome in a preparation stage, especially area studies and cultural awareness ones. Practical information is to be provided before and on the arrival. Besides training, mentors' and assistants' roles are of a key importance in preparation stage as well. A mentor cannot only hasten the introduction stage, but also serve a guide in terms of organizational structure and cultural issues. Mentor's knowledge would be very valuable in preparing the faculty member for the exchange experience. A mentor could also be a faculty member at the host institution who works with the faculty member coming on an exchange program prior to their arrival. Traditions, teaching methods, studies' programs, specific requirement of students, rating or grading schemes, teaching means (IT, libraries, books) are important to know before going to teach abroad. The host institution mentor should continue to mentor the faculty member during teaching assignments providing valuable ongoing information. In addition to the mentor, it is helpful to have an administrative assistant who helps the faculty member with administrative issues such as ensuring the proper books are ordered for the class, that computers are set up and available for use upon arrival, and that any personnel issues are completed. Daily assistance is related to practical information provision as well as general exchange process quality management. An informative welcome package with details on living and working issues, travelling within and out of the city schemes, eating, sport, cultural and health facilities, institutional specifics covering organizational structure and historical backgrounds, customs and local traditions, specific requirements at classrooms, teaching practices, students' rating practices, electronic means and internet facilities as well as libraries, etc., would not only save time for exchange faculty and assisting personnel, but also protect from various cultural miscommunication or misperception issues.

Having an assigned person, such as an administrative assistant, to provide active help before and during stay would be of a key importance, as it is very convenient to have a contact person regarding various daily issues. In order to meet the needs and requirements of both the incoming foreign faculty as well as thestudents at host institution, special questionnaires before the stay are highly recommendable. Experience sharing with former exchange faculty, receptions during stay at host institution or some common activities (sports, cultural events, etc.) would also serve as effective tools in increasing cultural and practical awareness of visiting faculty.

Process quality management involves active cooperation of both the home and host institutions. The home institution's active involvement in selection of appropriate candidate, as well as help in preparation stage shall have a significant impact on faculty performance abroad. A serious approach to any feedback during or after a faculty stay, and appropriate reaction in modifying welcome package or preparation stage trainings would serve as a helpful instrument as well.

\section{Conclusion}

As we specified, globalization is becoming increasingly important in business education. Although there are multiple strategies available to globalize business education, faculty globalization is important area to consider. The preparation stage, need for daily assistance, and the process quality management are critical to make a faculty exchange successful. Daily assistance, the presence of a mentor, institutional cooperation, and personal efforts of the individual are all important. The interaction of these components can make a faculty exchange very beneficial to the faculty member and both the host and home institutions. Ultimately, the students of both institutions will benefit from a successful faculty exchange.

\section{References}

AACSB. (2004). International-The Association to Advance Collegiate School of Business. Eligibility procedures and standards for business accreditation. St. Louis, MO, USA.

AACSB. (2011). The Globalization of Management Education: Changing International Structures. Adaptive Strategies, and the Impact on Institutions. 
Arkoudis, S. (2006). Teaching international students. Strategies to enhance learning. Centre for the Study of Higher Education. University of Melbourne.

Bao, L., \& Ferrara, M. S. (2009). A case study of a successful multicultural project: CCEP and the infusion of internationalization across the university. International Journal of Multicultural Education, 11(1), 1-10.

Carleton University. (2003). Undergraduate Calendar, 2003-04. Retrieved March 13, 2004, from http://www.carleton.ca/cuuc/programs/074program.html\#12

Cavusgil, S., Tamer, K. G., \& Riesenberg, J. R. (2008). International Business: Strategy, Management and the New Realities (pp. 556). Prentice Hall.

Dobbert, M. L. L. (1998). The impossibility of internationalizing students by adding materials to courses. In J. A. Mestenhauser \& B. J. Ellingboe (Eds.), Reforming the higher education curriculum: Internationalizing the campus (pp. 53-68). Phoenix, AZ, USA: Oryx Press.

Ellingboe, J. A. (1998). Divisional strategies to internationalize a campus portrait. In J. A. Mestenhauser \& B. J. Ellingboe (Eds.), Reforming the higher education curriculum: Internationalizing the campus. Phoenix, AZ, USA: Oryx Press.

Ghemawat, P. (2011). Bridging the globalization gap at top business schools: Curricular challenges and a response. In J. Canals (Ed.), The Future of Leadership Development. Houndmills, Hampshire: Palgrave Macmillan.

Griffin, P. A. (1999). The incorporation of internationalization into adult and higher education curricula. Paper presented at the annual meeting of the Comparative International Education Society, Toronto, Ontario, Canada.

Hall, D. E. (2007). Why professors should teach abroad. The Chronicle of Higher Education, 54(6), 20.

Hanson, K. H., \& Meyerson, J. (1995). International challenges to American colleges and universities: Looking ahead. Pheonix, AZ, USA: American Council on Education and Oryx Press.

Harris, M. (1993). The international business curriculum in independent liberal arts colleges and Universities. A report. Washington D.C., USA: Council of Independent Colleges.

Kendrick, J. (1993). Universities, corporations report progress in integrating total quality into curriculums. Quality, 32(1), 13.

Knight, J. (2003). Updated internationalization definition. International Higher Education, 33, 2-3.

Kwok, C. C. Y., \& Arpan, J. S. (2002). Internationalizing the business school: A global survery in 2000. Journal of International Business Studies, 33(3), 571-581. http://dx.doi.org/10.1057/palgrave.jibs.8491032

Kwok, C., \& Arpan, J. (1994). A comparison of international business education at U.S. and European business schools in the 1990's. Management Information Review, 34(4), 357-379.

Leinwand, G. (1983). Without a nickel: The challenge of internationalizing the curriculum and the campus. Washington D.C., USA: American Association of State Colleges and Universities.

Loch, K., \& Deans, P. (1997). Is there a difference or who's doing what? A comparison of AACSB accredited and non-accredited schools' internationalization of the information systems curriculum (pp. 38-47). Proceedings of the International Academy for Information Management Annual Conference, Atlanta GA, USA.

Lorange, P. (2003). Global responsibility-business education and business schools: Roles in promoting a global perspective. Corporate Governance, 3(3), 126. http://dx.doi.org/10.1108/14720700310483514

Mestenhauser, J. A. (1998). Portraits of an international curriculum: An uncommon multidimensional perspective. In J. A. Mestenhauser \& B. J. Ellingboe (Eds.), Reforming the higher education curriculum: Internationalizing the campus (pp. 3-35). Phoenix, AZ, USA: Oryx Press.

Newman, H. (1999). The Idea of a University. Washington: Regenery Publishing Inc.

Pisani, N. (2009). International management research: Investigating its recent diffusion in top management journals. Journal of Management, 35(2), 199-218. http://dx.doi.org/10.1177/0149206308321552

Queen's School of Business. (2003). School of business-commerce program calendar. Retrieved March 17, 2004, from http://www.queensu.ca/calendars/business/COMM.htm

Raby, R. L. (1996). Internationalizing the Curriculum. In R. L. Raby \& N. Tarrow (Eds.), Dimensions of the 
community college: International, interncultural, and multicultural perspectives (pp. 111-143). New York, USA: Garland Publishing Inc.

Satterlee, B. (1997). Internationalizing graduate-level business curricula. (Report No. HE030322). Florida, USA: Warner Southern College, Division of Adult \& Continuing Education. (ERIC Document Reproduction Service No. ED 410787)

Skousen, F., \& Bertelsen, D. (1994). A look at change in management education. SAM Advanced Management Journal, 59(1), 13-20.

Ward, C., \& Kennedy, A. (1993a). Where's the cultural in cross-cultural transition? Comparative studies of sojourner adjustment. Journal of Cross-cultural Psychology, 24, 221-249. http://dx.doi.org/10.1177/0022022193242006

Ward, C., \& Kennedy, A. (1993b). Psychological and sociocultural adjustment during cross-cultural transitions: A comparison of secondary school students at home and abroad. International Journal of Psychology, 28, 129. http://dx.doi.org/10.1080/00207599308247181

Ward, C., Berno, T., \& Kennedy, A. (2000, September). The expectations of international students for study abroad. Paper presented at the International Conference on Education and Migrant Societies, Singapore.

Ward, C., Bochner, S., \& Furnham, A. (2001). The psychology of culture shock. London: Routledge.

Warzyn, D. (1997). Internationalizing the curriculum: A case study in the business division. Procedings of sixth annual international conference for community \& technical college chairs. deans and other organizational leaders, Reno, NV, USA 102-125.

Wood, R. C. (1977). The twenty-first century is now. Educational Record, No. 58 \#1 8-30.

Zoffer, D. (1987). Accreditation bends before the winds of change. Educational Record, Winter, 43-46.

\section{Note}

Note 1. Estimations from The Open Doors Report, 2013.

\section{Copyrights}

Copyright for this article is retained by the author(s), with first publication rights granted to the journal.

This is an open-access article distributed under the terms and conditions of the Creative Commons Attribution license (http://creativecommons.org/licenses/by/3.0/). 